\title{
Embedding of Bacterial Cellulose Nanofibers within PHEMA Hydrogel Matrices: Tunable Stiffness Composites with Potential for Biomedical Applications
}

\author{
Radka Hobzova $\mathbb{D}^{1},{ }^{1}$ Jakub Hrib, ${ }^{1}$ Jakub Sirc, ${ }^{1}$ Evgeny Karpushkin, ${ }^{1}$ Jiri Michalek, ${ }^{1}$ \\ Olga Janouskova, ${ }^{1}$ and Paul Gatenholm ${ }^{2}$ \\ ${ }^{1}$ Institute of Macromolecular Chemistry, Czech Academy of Sciences, Heyrovsky Sq. 2, 16206 Prague 6, Czech Republic \\ ${ }^{2}$ Department of Chemical and Biological Engineering/Biopolymer Technology and Wallenberg Wood Science Center, \\ Chalmers University of Technology, Kemivagen 10, 41296 Gothenburg, Sweden \\ Correspondence should be addressed to Radka Hobzova; hobzova@imc.cas.cz
}

Received 20 July 2017; Revised 30 November 2017; Accepted 18 December 2017; Published 17 January 2018

Academic Editor: Faheem Ahmed

Copyright ( 2018 Radka Hobzova et al. This is an open access article distributed under the Creative Commons Attribution License, which permits unrestricted use, distribution, and reproduction in any medium, provided the original work is properly cited.

\begin{abstract}
Bacterial cellulose (BC) and poly(2-hydroxyethyl methacrylate) (PHEMA) hydrogels are both considered as biocompatible materials with potential use in various biomedical applications including cartilage, cardiovascular stent, and soft tissue engineering. In this work, the "ever-wet" process based on in situ UV radical polymerization of HEMA monomer in BC nanofibrous structure impregnated with HEMA was used, and a series of BC-PHEMA composites was prepared. The composite structures were characterized by ATR FT-IR spectroscopy, WAXD, SEM, and TEM techniques. The strategy of using densified BC material of various cellulose fiber contents was applied to improve mechanical properties. The mechanical properties were tested under tensile, dynamic shear, and relaxation modes. The final composites contained 1 to $20 \mathrm{wt} \%$ of BC; the effect of the reinforcement degree on morphology, swelling capacity, and mechanical properties was investigated. The biocompatibility test of BC-PHEMA composites was performed using mouse mesenchymal stem cells.
\end{abstract}

\section{Introduction}

Bacterial cellulose $(\mathrm{BC})$ has gained considerable attention in recent years because of its unique structure and properties. $\mathrm{BC}$ is produced by bacteria Gluconacetobacter xylinus in the form of tree-dimensional network of nanosized fibrils (fiber diameter $20-100 \mathrm{~nm}$ ). The remarkable features of BC, which set it apart from common plant cellulose, are the very high purity, high crystallinity (80-90\%), high water holding capacity (99\% water), and good mechanical stability $[1,2]$. Moreover, the possibility of direct control of the biosynthesis process in terms of final structure and shape together with inherent biocompatibility and nontoxicity of $\mathrm{BC}$ makes this biopolymer a promising candidate for various biomedical applications such as wound dressings, artificial skin, scaffolds for tissue engineering, and soft tissue replacement [3-9].

A number of researchers focused on preparation of mechanically enhanced BC composites [10] as the scaffolds fabricated directly from pure BC show mechanical anisotropy with a high tensile modulus $(E=2.9 \mathrm{MPa})$ along the fibril layer direction but a low compression modulus $(E=$ $0.007 \mathrm{MPa}$ ) perpendicular to the stratified direction [11]. BC composites have been prepared by addition of reinforcing agents during the $\mathrm{BC}$ biosynthesis (e.g., using silica [12], titania [13], or silver [14] nanoparticles as fillers), by blending of $\mathrm{BC}$ with various polymers (e.g., with chitosan [15], polyvinyl alcohol [16, 17], or acrylic resin [18]) or by in situ polymerization of monomers within the BC network (e.g., (meth)acrylates [19-23] or (meth)acrylamides [24-26]).

In our previous work [21] we have demonstrated a successful preparation of various BC-methacrylate composites by UV radical crosslinking polymerization of monomer/ crosslinker mixtures by the "ever-wet" process by impregnating the $\mathrm{BC}$ nanofibrous structures with the monomers (2-hydroxyethyl methacrylate, glycerol monomethacrylate, and/or 2-ethoxyethyl methacrylate). We have shown that the 
final properties of the composites, especially the swelling and mechanical properties, can be adjusted in a relatively wide range of values. The properties of such composites were controlled by the chemical composition of the hydrogel matrix (i.e., by monomer ratio, crosslink density, or diluent concentration) while keeping the BC content at the level of $1 \mathrm{wt} \%$. Other authors $[19,27,28]$ studied BC composites of different $\mathrm{BC}$ content and showed that mechanical improvement can be achieved, so that these densified BC scaffolds almost approached the mechanical requirements of the native tissue.

The objective of this work was the preparation of mechanically enhanced BC-methacrylate composites, where the final properties will be mainly adjusted by the degree of reinforcement, that is, by the $\mathrm{BC}$ content in composites. As a suitable monomer for hydrogel matrix, 2-hydroxyethyl methacrylate (HEMA) was chosen because HEMA hydrogels are nontoxic and biocompatible with longtime and widespread use in the biomedical applications such as contact lenses, intraocular lenses, or implants for tissue engineering [29]. Therefore, combined with BC the high attractiveness in the field of biomaterials is ensured. The high-modulus and strength composites described here are considered for candidates for cartilage, stent, and certain wound-dressing materials. The PHEMA-based ointment has been commercialized (HEMAGEL ${ }^{\circledR}$ ) as a successful wound-healing and eczema-healing material [30].

The BC-PHEMA composites studied here were prepared by UV radical polymerization using "ever-wet" process. The amount of water present in the BC sheets was adjusted mechanically, and water was subsequently replaced by the monomer mixture. In this way, the BC/PHEMA ratio in the composite was controlled. The composite materials were characterized by swelling; morphology; mechanical properties in tensile, shear, and relaxation modes; biocompatibility.

\section{Materials and Methods}

2.1. Chemicals and Materials. 2-Hydroxyethyl methacrylate (HEMA) (Roehm GmbH), ethylene dimethacrylate (EDMA) (Aldrich), and Darocur ${ }^{\circledR} 1173$ (2-hydroxy-2-methylpropiophenone) were supplied by Sigma-Aldrich (Czech Republic) and used as received. Phosphate buffered saline (PBS, pH 7.4) was prepared from tablets (Sigma-Aldrich, Czech Republic). Cell culture Dulbecco's modified Eagle medium (DMEM) and AlamarBlue Assay were purchased from ThermoFisher Scientific (Czech Republic), 24-well plates from TPP (Techno Plat Product, iBioTech, Czech Republic), and biopsy punch Stiefel from Servoprax (Wesel, Germany). Mouse mesenchymal stem cells were kindly provided by Dr. Jendelova (Institute of Experimental Medicine AS CR, Prague, Czech Republic).

2.2. Preparation of $B C$. A corn steep liquor medium was used for cultivation of precultures and bacterial cellulose production as described elsewhere [31]. Precultures of $A$. xylinum subsp. sucrofermentans, BRP2001, trade number 700 $178^{\mathrm{TM}}$, purchased from the American Type Culture Collection (LGC Promochem AB, Borås, Sweden), were prepared as described by Bodin and coworkers [31]. Bacteria preculture suspension $(2.5 \mathrm{ml}$, cell density $3.7-10 \mathrm{cfu} / \mathrm{ml})$ was added to each glass bioreactor, and reactors were then put into an incubator at $30^{\circ} \mathrm{C}$ and cultivated for 7 days. Fermented BC sheets were removed from bioreactors and purified using $0.1 \mathrm{M} \mathrm{NaOH}$ at $60^{\circ} \mathrm{C}$ and then rinsed with distilled water.

The BC sheets of the original cellulose content of $1 \mathrm{wt} \%$ were compressed to obtain $\mathrm{BC}$ material with increased cellulose content of 5,10 , and $20 \mathrm{wt} \%$, using the protocol described elsewhere [9].

\subsection{Preparation of BC-PHEMA Composites. The BC-PHEMA} composites were prepared by crosslinking radical polymerization of mixture impregnated into the BC nanofibrous network. We followed the methods described in our previous work [21]. The polymerization mixture consisted of monomer (HEMA), crosslinker (EDMA, $0.7 \mathrm{wt} \%$ relative to monomer), $\mathrm{UV}$ initiator (Darocur, $0.5 \mathrm{wt} \%$ relative to monomer), and diluent (water). The water present in BC sheet was included into the overall calculation of diluent amount to keep the monomer/diluent (HEMA/water) ratio constant at 60/40.

$\mathrm{BC}$ sheets in the form of discs $8 \mathrm{~cm}$ in diameter were immersed into the polymerization mixtures, bubbled with nitrogen for $10 \mathrm{~min}$, and left for $24 \mathrm{~h}$ at room temperature under shaking to allow the liquid interchange. To obtain samples with defined BC content, the sheets were examined gravimetrically; the excess of monomer mixture was expelled to obtain the same sheet weight as before immersion.

The sheets were placed on a glass plate and confined with a silicone rubber frame of $1.0 \mathrm{~mm}$ thickness, covered with a polypropylene plate, and firmly closed with screw clamps into the mold. The polymerization was carried out by illumination with a UV lamp ReptiGlo 8.0 (60 W) for $20 \mathrm{~min}$. The obtained composites were washed in distilled water for five days (water was changed twice per day) to acquire an equilibrium swollen state. During the swelling, unreacted residues present in samples after the polymerization were washed out. The washing efficiency was checked by UV spectroscopy. The values of absorbance of the aqueous extract after 5 days were below the detection limit. The neat PHEMA hydrogel matrix was prepared under the same polymerization conditions as the BC-PHEMA composites.

2.4. Characterization of BC-PHEMA Composites. The equilibrium water content (EWC) was determined using weighing method. Specimens $(1 \times 1 \mathrm{~cm}$ approx. $)$ were cut from each equilibrium swollen material at room temperature. Excess surface liquid was gently blotted with tissue paper, and the samples were weighed $\left(m_{\mathrm{sw}}\right)$, then dried in free air at room temperature for 1 day, and finally dried under vacuum at elevated temperature $\left(30 \mathrm{~Pa}\right.$ at $\left.100^{\circ} \mathrm{C}\right)$ to constant weight $\left(m_{\mathrm{dry}}\right)$. The EWC is defined as EWC $=100 \times\left(m_{\mathrm{sw}}-m_{\mathrm{dry}}\right) / m_{\mathrm{sw}}$. The resulting EWC is expressed as the average of at least six values (three values of at least two independently prepared materials of the same composition $) \pm$ standard deviation $(n=$ $6)$.

ATR FT-IR spectra were measured on a Perkin-Elmer PARAGON 1000PC spectrometer equipped with Specac MKII Golden Gate Single Reflection ATR System with diamond crystal (angle of incidence $45^{\circ}$ ). Wide-angle X-ray 


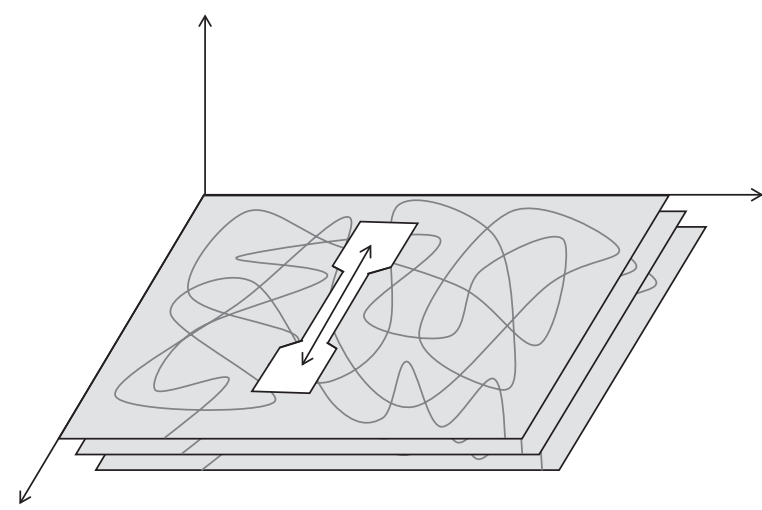

(a)

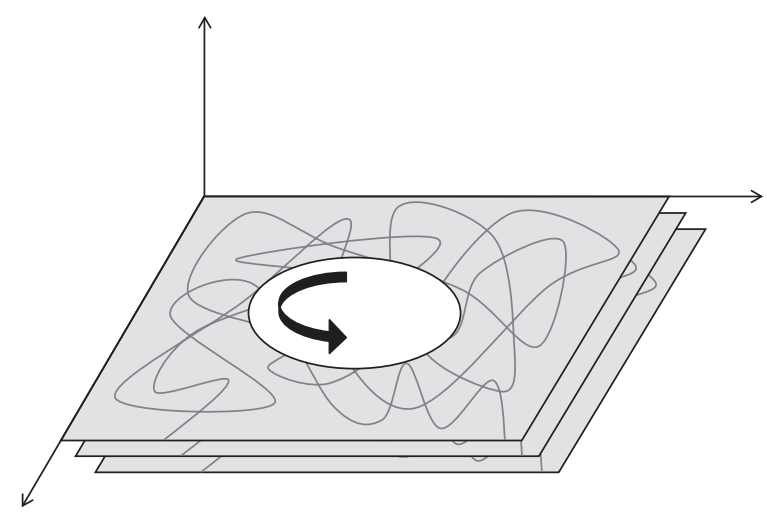

(b)

FIGURE 1: Schematic sketch of cut specimens and the direction of applied mechanical stresses in (a) static tensile and (b) dynamic shear measurements.

diffraction (XRD) patterns were obtained using high resolution diffractometer Explorer (GNR Analytical Instruments, Italy). Instrument was equipped with one-dimensional silicon strip detector Mythen 1K (Dectris, Switzerland). Samples were measured in reflection mode. The radiation $\mathrm{CuK} \alpha$ (wavelength $\lambda=1.54 \AA$ ) monochromatized by Ni foil $(\beta$ filter) was used for diffraction. The measurement was done in range $2 \theta=8-30^{\circ}$ with step $0.1^{\circ}$. Exposure time at each step was 10 seconds. Peak deconvolution procedure was made using the SASfit software [32]. The peak positions were employed to obtain periodicities and distinguish various phases according to Bragg's law, $d=\lambda / 2 \sin \theta$, where $\lambda$ is the $\mathrm{X}$-ray wavelength and $2 \theta$ is the scattering angle.

2.5. Morphology. Scanning electron microscopy (SEM) was carried out with a SEM microscope Quanta 200 FEG (FEI, Czech Republic). Samples in dry state were fractured in liquid nitrogen (in order to avoid plastic deformations during fracture) perpendicularly to the stratified structure of BC. The fractured surfaces were sputtered with $4 \mathrm{~nm}$ thin platinum layer (vacuum sputter coater SCD 050, Leica). Samples were observed in the SEM microscope using secondary electrons detector either at medium accelerating voltage of $15 \mathrm{kV}$ in low-vacuum $(80 \mathrm{~Pa})$ or at low accelerating voltage of $5 \mathrm{kV}$ in high vacuum $\left(10^{-3} \mathrm{~Pa}\right)$.

Transmission electron microscopy (TEM) was made with a TEM microscope Tecnai G2 Spirit (FEI, Czech Republic). The ultrathin sections $(40 \mathrm{~nm})$ of the investigated samples were cut with ultramicrotome (Ultrotome III, LKB) at room temperature. The sections were transferred to the TEM microscope and observed at $120 \mathrm{kV}$ using bright field imaging.

2.6. Mechanical Properties. The uniaxial extension test was done using the Instron 5800 with a crosshead speed of $10 \mathrm{~mm} / \mathrm{min}$ until failure. The dumbbell-shaped samples of width of $2 \mathrm{~mm}$ and thickness of $1 \mathrm{~mm}$ (ISO527-2/5B) were measured in their water-swollen state at room temperature.
The tests were carried out in the direction parallel to the stratified BC layers embedded in the hydrogel matrix (Figure 1(a)). The standard deviations of tensile strength $\left(\sigma_{b}\right)$, elongation at break $\left(\varepsilon_{b}\right)$, and Young modulus $(E)$ average were below $10 \%$.

The dynamic mechanical properties were characterized using the oscillation-shear rheometer Gemini HR Nano (Malvern/Bohlin) and the plate-plate geometry. The cylindrical-shaped samples (12.7 $\mathrm{mm}$ in diameter) were fixed between two parallel metal plates and measured in their equilibrium swollen state in water using a solvent chamber at $25^{\circ} \mathrm{C}$. The shear was introduced in the direction parallel to the stratified BC layers embedded in the hydrogel matrix (Figure 1(b)). The shear moduli $\left(G^{\prime}\right.$ and $\left.G^{\prime \prime}\right)$ were determined in the frequency range $0.01-100 \mathrm{~Hz}$. The measurements were done in the experimentally determined linear-viscoelastic limit of deformations below $0.05 \%$ strain.

The relaxation measurements were performed in both tensile and shear modes. The equilibrium swollen samples were strained to $0.05 \%$ and held for $3 \mathrm{~h}$ (shear measurements) or to $5 \%$ and held for $10 \mathrm{~min}$ (tensile measurements).

2.7. Biocompatibility Test. For biocompatibility test, equilibrium water-swollen samples were cut by biopsy punch $4 \mathrm{~mm}$ in diameter, and cut discs were sterilized under UV light for $30 \mathrm{~min}$. Mouse mesenchymal stem cells (rMSCs) were resuspended in fresh DMEM and seeded in the 24-well plates at a density of $5 \times 10^{4}$ cells/well. The insert (porosity $0.45 \mathrm{~mm}$, translucent PET membrane, Becton Dickenson, Czech Republic) with sample disc in $0.5 \mathrm{ml}$ of media was added above the cells. The cells were cultivated for $72 \mathrm{~h}$. The evaluation of growth and viability of cells was done by AlamarBlue Assay. The insert with sample was discarded, and AlamarBlue reagent was added to the medium with cells and incubated for $4 \mathrm{~h}$ at $37^{\circ} \mathrm{C}$. The viable/metabolically active cells reduced the active component of AlamarBlue reagent resazurin to resorufin, whose fluorescence was detected in a plate reader Synergy Neo (BioTek, Czech Republic) using excitation at $570 \mathrm{~nm}$ and emission at $60 \mathrm{~nm}$. The fluorescence intensity directly correlates with the number of 
TABLE 1: Specification and equilibrium swelling of BC-PHEMA composites.

\begin{tabular}{|c|c|c|c|c|}
\hline \multirow{2}{*}{ Material code } & \multicolumn{2}{|c|}{ BC content $[\mathrm{wt} \%]$} & \multicolumn{2}{|c|}{ Equilibrium water content [\%] } \\
\hline & Initial $^{\mathrm{a}}$ & Final $^{\mathrm{b}}$ & EWC- $1^{c}$ & EWC-2 ${ }^{\mathrm{d}}$ \\
\hline $\bar{M}$ & - & - & $40.6 \pm 0.1$ & $40.7 \pm 0.1$ \\
\hline $\mathrm{C} 1$ & 1 & 2 & $40.0 \pm 0.3$ & $40.1 \pm 0.2$ \\
\hline $\mathrm{C} 5$ & 5 & 8 & $39.8 \pm 0.3$ & $39.7 \pm 0.3$ \\
\hline $\mathrm{C} 10$ & 10 & 16 & $39.9 \pm 0.6$ & $39.8 \pm 0.5$ \\
\hline $\mathrm{C} 20$ & 20 & 30 & $39.5 \pm 0.1$ & $39.6 \pm 0.3$ \\
\hline
\end{tabular}

${ }^{\mathrm{a}} \mathrm{BC}$ content in the initial water-swollen $\mathrm{BC} ;{ }^{\mathrm{b}} \mathrm{BC}$ content in composite in dry state; ${ }^{\mathrm{c}} \mathrm{EWC}$ determined after preparation of composite prior to drying; ${ }^{\mathrm{d}} \mathrm{EWC}$ determined after drying of composite and its reswelling in water.

growing/viable cells. The acquired fluorescence was recalculated using a calibration curve to determine absolute number of viable cells under the sample. For calibration curve, 24-well plates were seeded with various numbers of cells, and the fluorescence of metabolized component resorufin was measured. Then, the cells were washed with PBS and incubated in $0.2 \mathrm{~mL}$ of trypsin solution $(0.05 \%$ trypsin, $0.5 \mathrm{mM}$ EDTA in PBS) at $37^{\circ} \mathrm{C}$ for $5-10 \mathrm{~min}$. The trypsin was deactivated by addition of $0.2 \mathrm{ml}$ of media. The cells were pipetted out from the well, transferred into the Eppendorf vial, and centrifuged for 3 minutes at $1200 \mathrm{rpm}$ at room temperature. The deactivated trypsin solution was then aspirated, and the pellet fraction (composed of cell and gel debris) was resuspended in $30 \mu \mathrm{L}$ of the PBS. The Bürker chamber was used to determine the number of cells per $1 \mathrm{~mL}$ of solution. To determine the number of viable cells, the $0.2 \%$ Trypan blue and lethal dyes were added in a $1: 1$ ratio. The numbers of viable cells were added to graph against fluorescent intensities, which gave us calibration curve and equation for the calculation of cell number growing under the insert with samples adequate to their fluorescent intensity. Each sample was conducted in triplicate, and the average values and their standard deviations were calculated.

The morphologies of cell growth under the insert with the samples and cell growth without sample (control) were visualized after $72 \mathrm{~h}$ of growth using the Olympus microscope equipped with camera Infinity 2 and FV10-ASW viewer software (Olympus, Japan). The images were evaluated using Quick photo 3.0 software.

\section{Results and Discussion}

3.1. Preparation of BC-PHEMA Composites. In our previous study [21], we demonstrated that by the combination of hydrophilic and hydrophobic monomers, it was possible to obtain composites having properties in a wide range of values. To achieve high level of compression modulus (6-8 MPa) and strength, addition of hydrophobic monomer (2-ethoxyethyl methacrylate) to hydrophilic major monomer was necessary. However, low swelling ( $2 \%$ of water) renders biomedical application of such composite material difficult. Using softer gels (e.g., based on HEMA monomer), an acceptable compromise between mechanical properties and swelling can be achieved. Here, we show that much stronger BC composites of a wide application range can be obtained by varying the BC content in the PHEMA matrix. As starting materials, BC gels with $99,95,90$, and $80 \%$ of water were used (see Table 1 , column "BC Content Initial"). If water present initially in the $\mathrm{BC}$ is completely replaced by the polymerization mixture, the $\mathrm{BC}$ content in the dry composite ranged from 2 to $30 \mathrm{wt} \%$ (see Table 1, column "BC Content Final").

The character of the samples is shown at Figure 2. The BC-PHEMA composites were considerably more translucent than the pure $\mathrm{BC}$, but still slightly opaque compared to neat PHEMA hydrogel matrix.

Figure 3 shows the ATR-IR spectra of pure BC, PHEMA matrix, and BC-PHEMA composites of various BC contents. The successful polymerization of HEMA monomer impregnated into the nanofibrous BC structure was confirmed by the appearance of peaks typical for methacrylate polymers at around $1720 \mathrm{~cm}^{-1}$ (carbonyl ester group), $1456 \mathrm{~cm}^{-1}$, and $750 \mathrm{~cm}^{-1}\left(\mathrm{CH}_{2}\right.$ group) and absence of the peak at 1630 attributed to the monomer. Comparing the spectra of composites, the intensity of peaks corresponding to PHEMA decreased with increased $\mathrm{BC}$ content. The presence of $\mathrm{BC}$ is demonstrated by the appearance of the peak at $1110 \mathrm{~cm}^{-1}$ corresponding to -C-O-C-vibration within the glucose ring which is evident in the spectra of both BC and composites. Finally, in all spectra the characteristic O-H group stretching peaks at $3350 \mathrm{~cm}^{-1}$ were detected as a contribution of both PHEMA and BC component.

The crystallinity character of the materials was examined by XRD, and the diffractograms are shown in Figure 4. For pure $\mathrm{BC}$ the main diffraction peaks are apparent at $2 \theta 14.5$, 16.7 , and $22.6^{\circ}$, while PHEMA matrix $(\mathrm{M})$ is characterized by a broad peak centered at around $2 \theta 18.5^{\circ}$ as typical for fully amorphous material. All BC-PHEMA composites exhibit the diffraction profiles very similar to that of pure $\mathrm{BC}$ regardless on $\mathrm{BC}$ content (therefore, only data for composites C5 and C10 are presented).

The equilibrium water content (EWC) of all prepared materials is given in Table 1. Only a slight decrease in swelling is observed when comparing hydrogel matrix $(\mathrm{M})$ and composite materials (marked as $\mathrm{C}$ with number corresponding to initial BC content). The EWC of composites are nearly the same with no obvious dependence on the $\mathrm{BC}$ content. Presumably, PHEMA matrix is a major determinant of the final EWC of the composites materials, irrespectively of the 


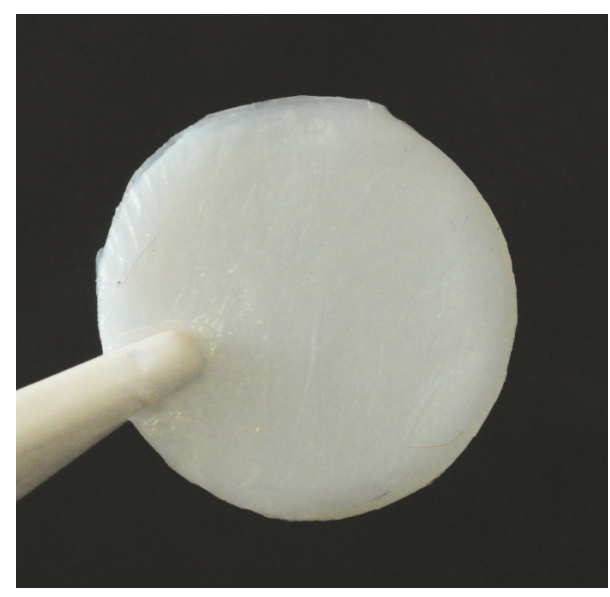

(a)

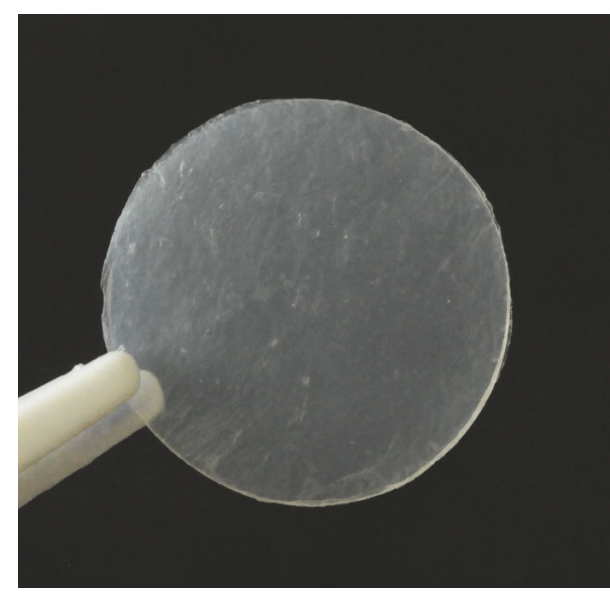

(c)

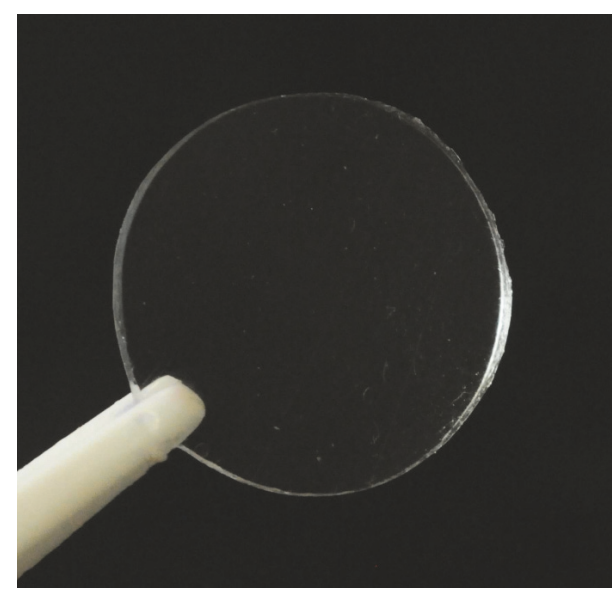

(b)

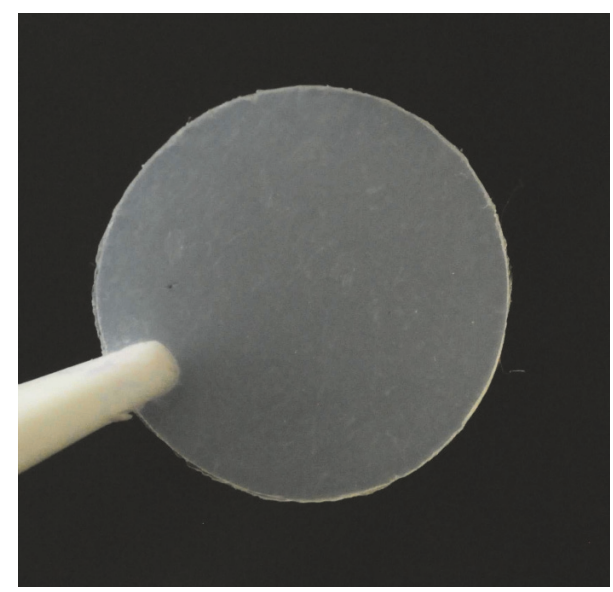

(d)

FIGURE 2: Photographs of water-swollen $\mathrm{BC}\left(90 \% \mathrm{H}_{2} \mathrm{O}\right)(\mathrm{a})$, PHEMA hydrogel matrix swollen in water (b), BC-PHEMA composite C10 in dry (c) and swollen state (d).

BC content in the matrix. The composites as well as PHEMA matrix swelled reversibly after drying; compare the EWC1 and EWC-2 values in Table 1. The formation of PHEMA matrix within $\mathrm{BC}$ nanofibrous network prevents the collapse of the $\mathrm{BC}$ structure and provides the materials with repeatable ability to swell. This is a favorable feature of the material enabling the storage of composites in the dry form to ensure easier sterility.

\subsection{Morphology. The morphology of BC-PHEMA compos-} ites was examined by SEM. Figures 5(a)-5(c) illustrate the structure of the composites varying in $\mathrm{BC}$ content. The micrographs show darker PHEMA matrix background with light BC nanofibers protruding to the surface. There are no apparent fibers in the structure, but only white dots distributed in the hydrogel matrix, whose number increases with the increasing $\mathrm{BC}$ content in the matrix. To prove that the "light dots" represent the BC fibers, we specially prepared hybrid sample of a two-layer structure. The BC sheet swollen in the polymerization mixture was polymerized "in air" contrary to the standard preparation of the composite which is carried out in closed mold. Oxygen present in polymerization mixture acts as an inhibitor of the radical polymerization and causes that polymerization not to be complete in the surface layer, and therefore no compact hydrogel matrix is formed as in the inner layers of the composites. The structure of such a sample is shown in Figure 5(d); the lower part of the image represents a surface layer of the sample with the partially preserved BC fiber structure and the upper part of the image shows the structure of the inner layer. This is consistent with the structures of the composites C5-C20. It can be concluded that the light dots really do represent $\mathrm{BC}$ fibers, where individual $\mathrm{BC}$ nanofibers are well wrapped by the PHEMA and are uniformly dispersed in compact hydrogel matrix. The homogenous distribution of the $\mathrm{BC}$ fibers within the hydrogel matrix without noticeable aggregates formation is also clearly seen in TEM images of sample cross-section showing lighter PHEMA matrix with darker spots or fibers of BC (Figure 6). The results obtained by the morphological analysis confirm successful impregnation of BC nanofibrous network by HEMA monomer and in particular the excellent compatibility between the BC and 


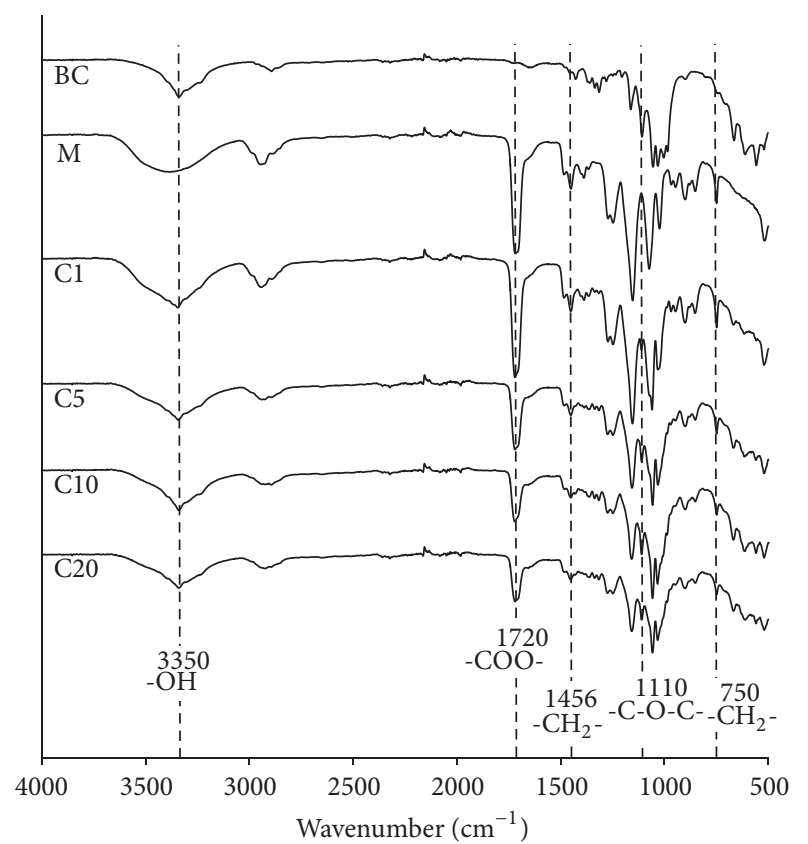

FIgURE 3: IR spectra of BC, PHEMA hydrogel matrix (M), and CBPHEMA composites ( $\mathrm{C} 1, \mathrm{C} 5, \mathrm{C} 10$, and $\mathrm{C} 20)$.

PHEMA matrix with strong interfacial adhesion arising from the presence of hydroxyl groups in both materials.

\subsection{Mechanical Properties}

Static Tensile Properties. Measurements in uniaxial tension were performed for PHEMA hydrogel matrix $\mathrm{M}$ and $\mathrm{BC}-$ PHEMA composite C10 (Figure 7). The shapes of both curves are characteristic for viscoelastic materials that do not exhibit linear stress/strain behavior at low deformations. The difference in stress (Young modulus) is enormous (see the insert in Figure 7).

The mechanical parameters are presented in Table 2 together with those for pure BC [11]. The introduction of BC fibers improved the strength and stiffness of PHEMA and $\mathrm{BC}$ significantly. Taking the composite $\mathrm{C10}$, the tensile strength increased by a factor of 80 and 10, respectively, compared to hydrogel matrix and BC; for Young modulus, $E$, the factors were 120 and 40 , respectively. The elongation at break decreased only by a factor of 2 compared to the hydrogel matrix and was even slightly higher than that of the parent BC. Such improvement in mechanical properties for hydrogel composites is not associated with a change in swelling, because EWC values are practically the same compared with PHEMA matrix (see Table 1). The considerable reinforcement by incorporation of $\mathrm{BC}$ into PHEMA matrix is apparently caused by good wetting of BC fibers with HEMA and their good adhesion to the matrix. The strength and modulus are almost of an order of magnitude better than that for interpenetrating polymer networks or fiber-reinforced hydrogels [33], but the latter contain much more water. The compact structure with good interfacial adhesion between matrix and $\mathrm{BC}$ fibers was also proved by electron microscopy.
TABLE 2: Mechanical properties of hydrogels.

\begin{tabular}{lccccc}
\hline \multirow{3}{*}{ Material code } & $\sigma_{b}$ & $\varepsilon_{b}$ & $E$ & $G^{\prime}$ & $G^{\prime \prime}$ \\
& $(\mathrm{MPa})$ & $(\%)$ & $(\mathrm{MPa})$ & $(\mathrm{kPa})$ & $(\mathrm{kPa})$ \\
\hline $\mathrm{BC}$ & $2.2^{\mathrm{a}}$ & $21.0^{\mathrm{a}}$ & $2.9^{\mathrm{a}}$ & 0.63 & 0.07 \\
$\mathrm{M}$ & 0.3 & 51.4 & 1.0 & 117 & 16 \\
$\mathrm{C} 1$ & 8.7 & 38.7 & 15.2 & 510 & 70 \\
$\mathrm{C} 10$ & 25.3 & 25.5 & 120 & 1450 & 187 \\
\hline ligament & $38.6^{\mathrm{b}}$ & $17.0^{\mathrm{b}}$ & $332^{\mathrm{b}}$ & & \\
\hline
\end{tabular}

${ }^{\mathrm{a}}$ Values of tensile properties for pure BC taken from [11]. ${ }^{\mathrm{b}}$ Values of tensile properties for natural ligament taken from [25]. ${ }^{\mathrm{C}}$ Moduli values at $1 \mathrm{~Hz}$.

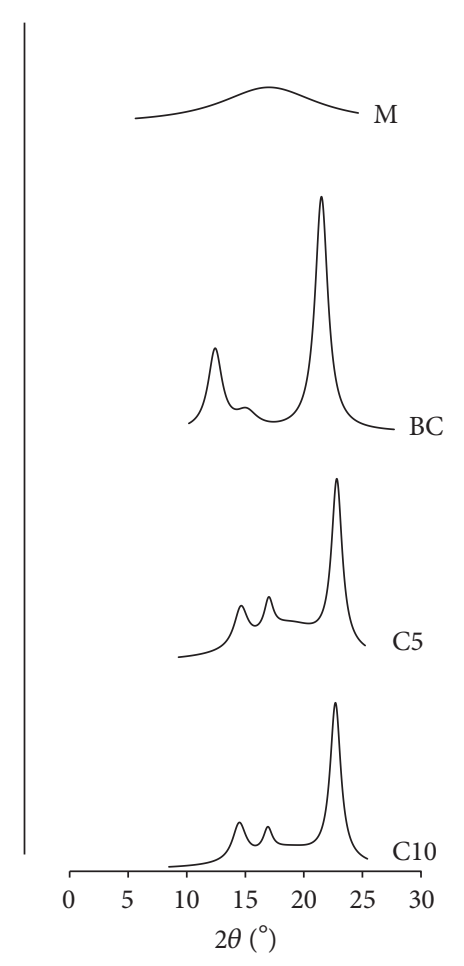

Figure 4: X-ray diffractograms of BC, PHEMA hydrogel matrix (M), and CB-PHEMA composites (C1, C5, C10, and C20).

The values of tensile properties of composite $\mathrm{C} 10$ approach the values for natural ligament [25] (Table 2). It can be concluded that the composite $\mathrm{C} 10$ mimics well the structure of the ligament; that is, both materials are composed of a soft hydrated matrix reinforced by filaments.

Dynamic Mechanical Properties. Dynamic mechanical behavior can be characterized by storage modulus $\left(G^{\prime}\right)$ which is associated with the elastic energy stored in the material and loss modulus $\left(G^{\prime \prime}\right)$ which describes the viscous behavior and is associated with the dissipation of the energy caused by structural rearrangements within the material.

Oscillatory shear measurements of equilibrium waterswollen hydrogel materials offer frequency dependences of $G^{\prime}$ and $G^{\prime \prime}$ (Figures 8 and 9). A slight increase in $G^{\prime}$ with frequency was observed for both the PHEMA matrix $\mathrm{M}$ and composites $\mathrm{Cl}$ and $\mathrm{C} 10$. The increase in $G^{\prime \prime}$ with frequency 


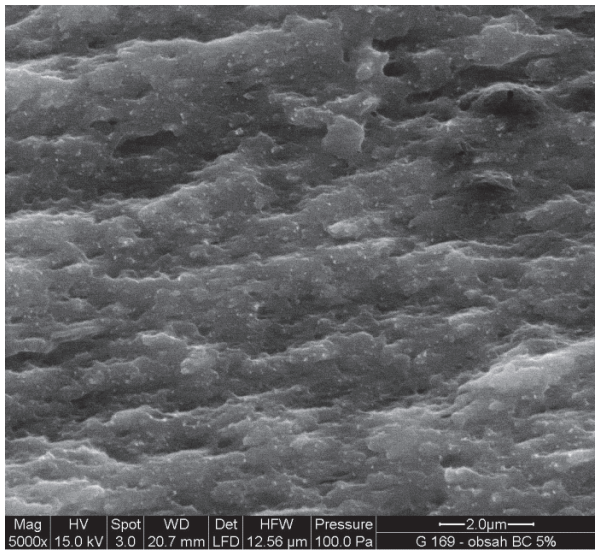

(a)

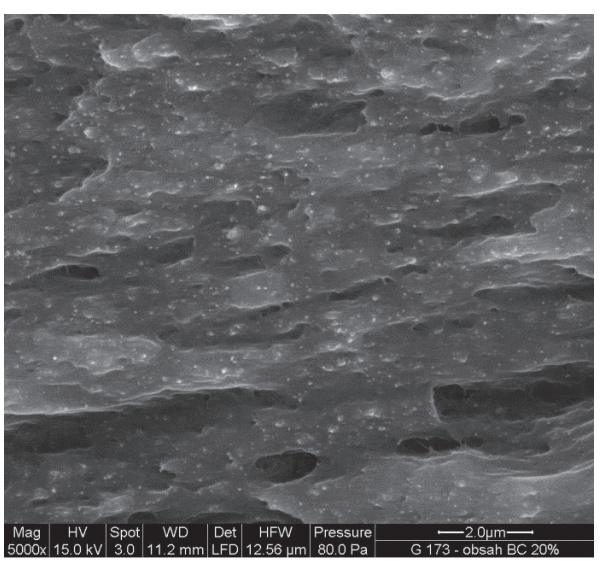

(c)

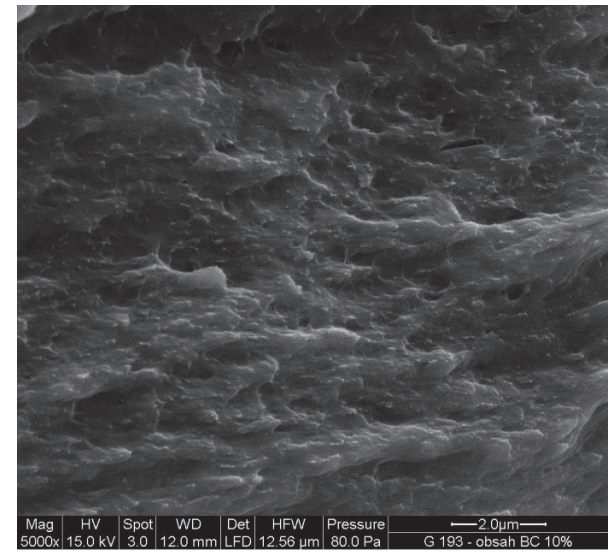

(b)

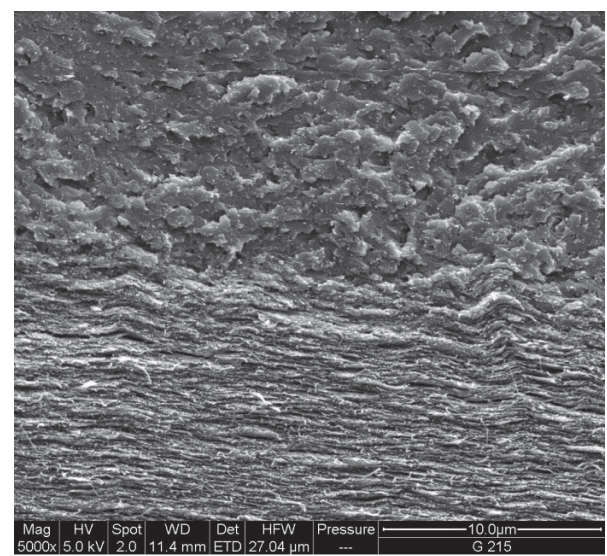

(d)

FIGURE 5: SEM micrographs of the fracture surface of dry BC-PHEMA composites with various BC contents: (a) composite C5, (b) composite C10, and (c) composite C20 (for the codes, see Table 1). (d) SEM micrograph of the composite with two-layer structure.

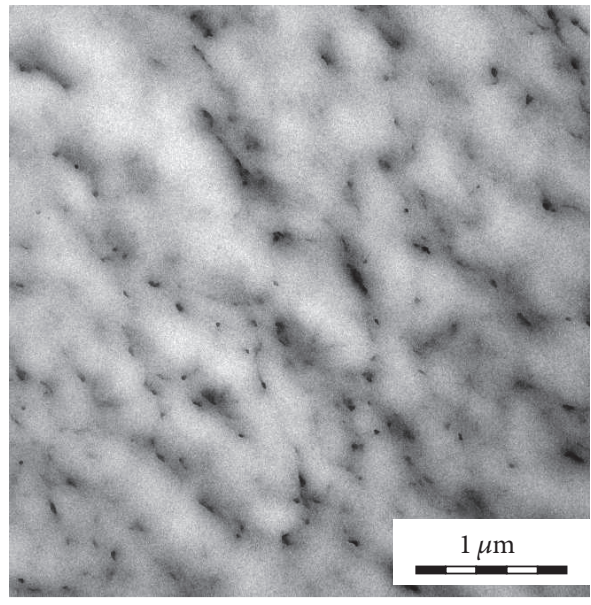

(a)

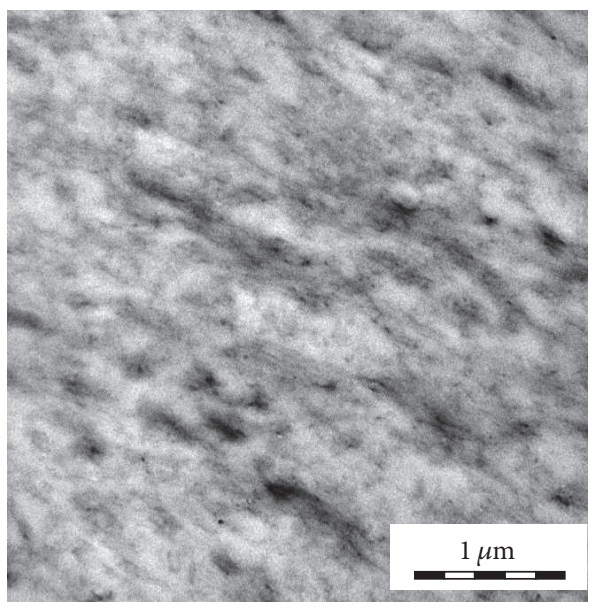

(b)

FIGURE 6: TEM micrographs of the fracture surface of dry BC-PHEMA composites (a) C5 and (b) C10 (for the codes, see Table 1). 


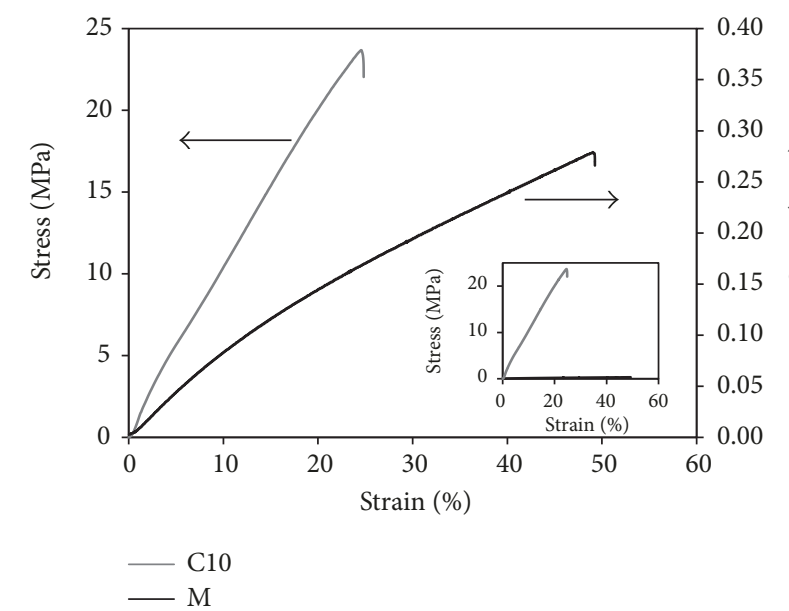

FIgure 7: Tensile stress-strain curves for PHEMA hydrogel matrix $\mathrm{M}$ (black line, right $y$ axis) and BC-PHEMA composite C10 (grey line, left $y$ axis).

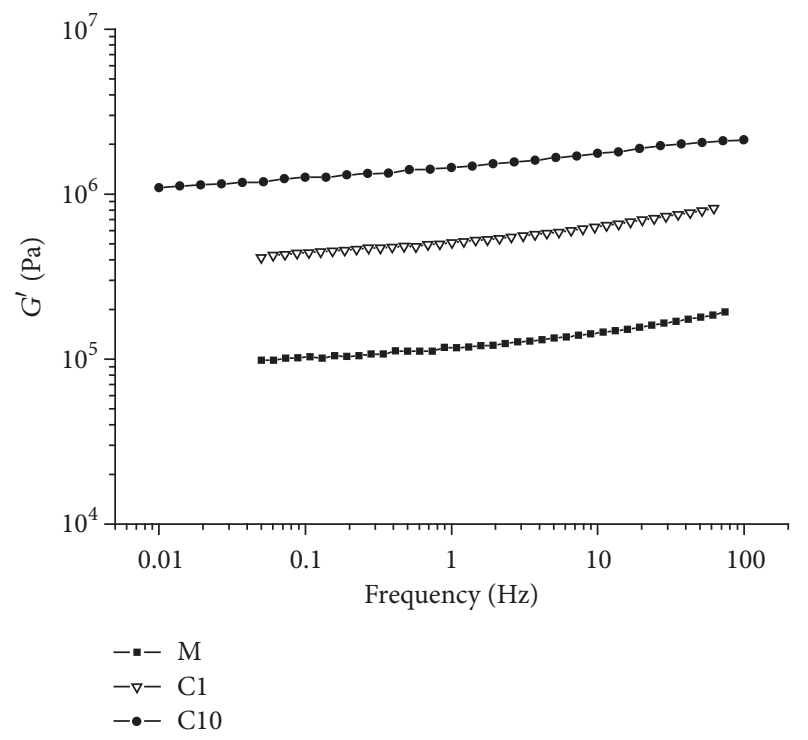

FIGURE 8: Frequency dependence of the storage moduli $G^{\prime}$ for PHEMA matrix M (symbol a), BC-PHEMA composite C1 (symbol $\nabla)$, and C10 (symbol $\bullet$ ).

implies the rubbery-like behavior of the materials (Figure 9). Similarly to tensile measurements, improvement of $G^{\prime}$ by $\mathrm{BC}$ reinforcement is evident (Table 2); the increase in $G^{\prime}$ (factor 12) is lower than the increase in $E$ (factor 120). This difference can be explained by the fact that oscillatory shear measurements are limited to small strains where the matrix is still disoriented, whereas in the (nonoscillatory) extension mode the chains can get oriented aided by the adhesion to nanofibers. The losses $\left(G^{\prime \prime}\right)$ are relatively low and the ratio $G^{\prime \prime} / G^{\prime}$ (loss-angle tangent) is almost the same.

Relaxation Properties Measurements. Since most natural soft tissues are of viscoelastic nature, the time-dependent properties of the designed material are very important. The

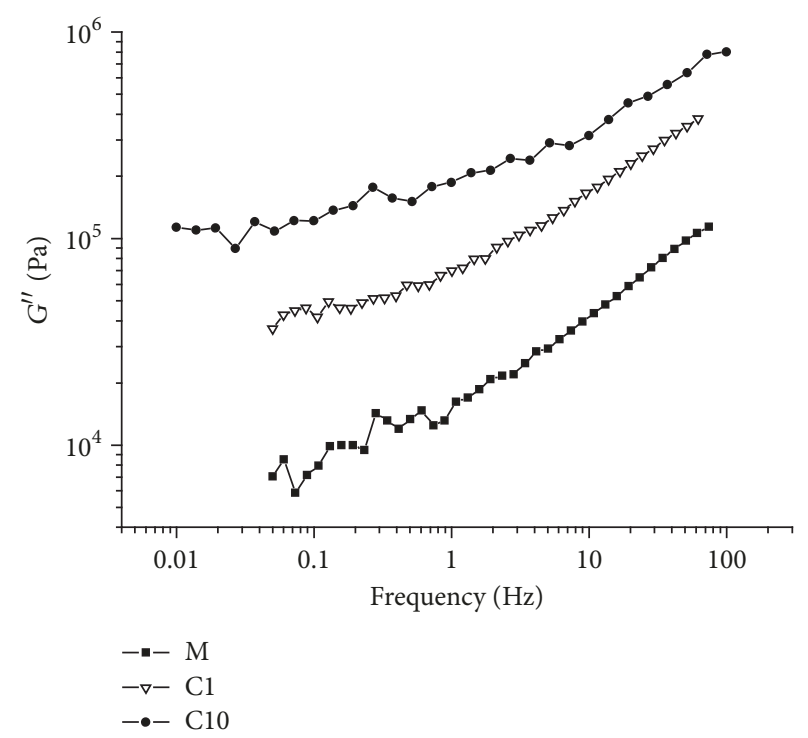

FIgURE 9: Frequency dependence of the loss moduli $G^{\prime \prime}$ for PHEMA matrix M (symbol - $)$, BC-PHEMA composite $\mathrm{Cl}$ (symbol $\nabla$ ), and C10 (symbol @).

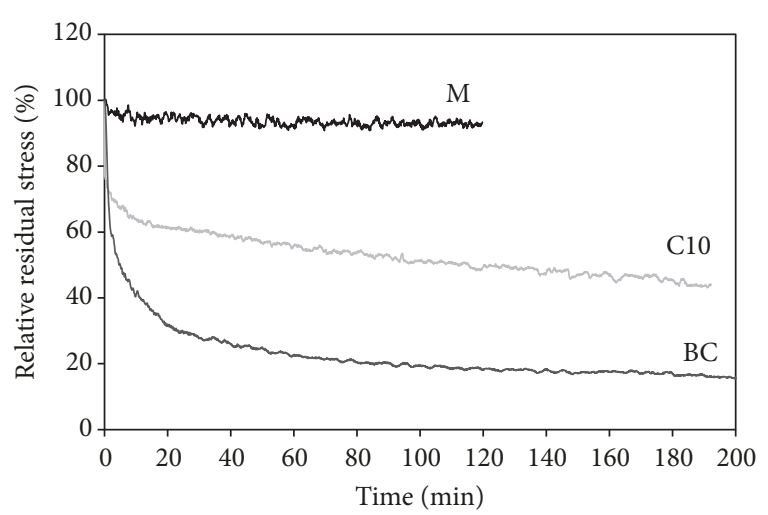

FIGURE 10: Change in relative residual shear relaxation stress over the time period of $3 \mathrm{~h}$ for pure $\mathrm{BC}$, PHEMA matrix $\mathrm{M}$, and $\mathrm{BC}$ PHEMA composite C10.

stress relaxation measurements were performed for pure BC, PHEMA matrix $\mathrm{M}$, and the composite $\mathrm{C} 10$. An instantaneous oscillatory deformation in shear was applied and the time dependence of the stress required for maintaining that deformation was recorded.

Very low deformations (0.05\%) were applied. For PHEMA hydrogel matrix almost no decrease in stress over the time was recorded (Figure 10), and the material showed almost ideal rubbery network behavior with immediate response to the applied deformation. On the other hand, a pronounced time-dependent relaxation behavior of both parent $\mathrm{BC}$ and composites was observed. BC relaxed much faster and to the lower final stress (20\% of residual stress) compared to composite C10 ( $45 \%$ of residual stress). Such a behavior suggests that even small mechanical loading causes the structural rearrangements (reorientation of $\mathrm{BC}$ nanofibers). These rearrangements take place much 


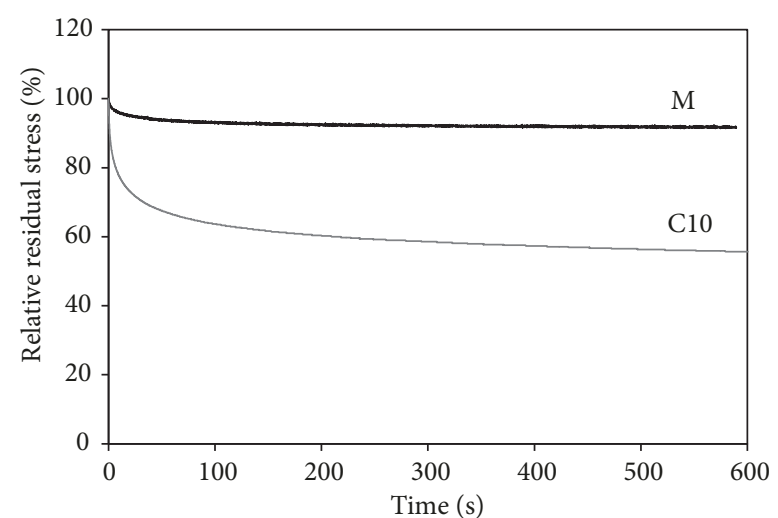

FIGURE 11: Change in relative residual tensile relaxation stress over the period time of 10 min for PHEMA matrix M and BC-PHEMA composite C10.

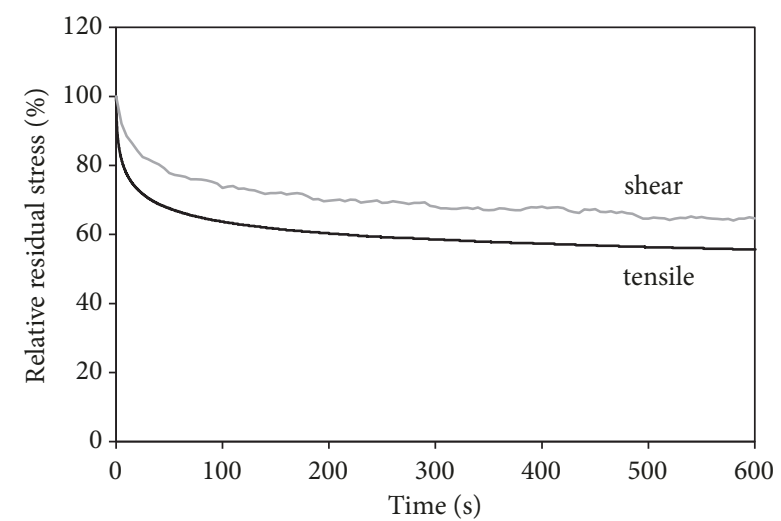

FIGURE 12: Comparison of relaxation response under tensile and shear deformation for BC-PHEMA composite C10.

easier in neat $\mathrm{BC}$ scaffold than in the composite material where the fibers are anchored in a hydrogel matrix. This interpretation was also supported by the results obtained from relaxation measurements under tensile deformation as shown in Figure 11. Comparing the relaxation response of BC-PHEMA composite under tensile and shear deformation, the tensile relaxation proceeds faster and to a lower residual stress (Figure 12). The observed viscoelastic behavior of BC-PHEMA composites can be considered similar to those of other composite natural tissues such as ligament, tendon, or cartilage $[34,35]$. It would be interesting to strain the composite in extension or compression during the process of network formation (irradiation), so as to reorient continuously the fibers and chains and to fix by crosslinking the reoriented structure. This may lead to further enhancement of mechanical properties.

3.4. Biocompatibility. The nontoxicity of BC and PHEMA hydrogel is known, nevertheless we performed the biocompatibility test with our BC-PHEMA composites using rMSCs. The behavior of these cells is an important indicator in terms of tissue engineering because they can be differentiated into a

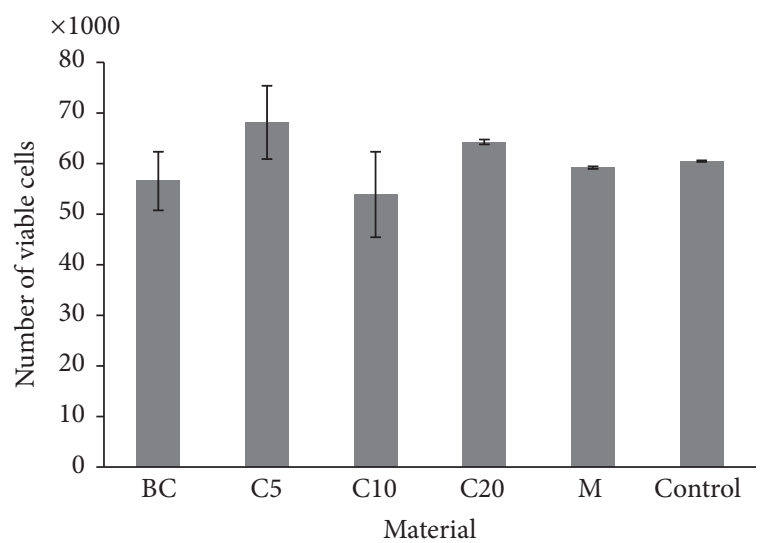

FIGURE 13: Number of viable rMSCs after $72 \mathrm{~h}$ of growth on BCPHEMA composites determined by cell viability AlamarBlue Assay.

variety of cell types, including osteocytes, adipocytes, or also chondrocytes.

We determined the number of growing/viable cells after $72 \mathrm{~h}$ under the BC, PHEMA matrix M, and BC-PHEMA composites incubated with the cells in the inserts. The influence of the sample presence on cell growing compared to the control test (without insert and any sample) is shown in Figure 13. It is apparent that the differences in number of viable cells between the samples and control as well as between the materials are not significant. Further, we observed the morphology of growing cells, and the microscopy images are shown in Figure 14. It can be concluded that the BC-PHEMA composites regardless of the composition did not influence the morphology and proliferation of the rMSCs.

\section{Conclusions}

Composite hydrogels based on poly(2-hydroxyethyl methacrylate) (PHEMA) matrix and bacterial cellulose nanofibers (BC) were successfully prepared by in situ UV radical polymerization of HEMA monomer impregnated into wet BC nanofibrous structure. The final properties of composites were tuned by varying the $\mathrm{BC}$ content ranging from 1 to $20 \mathrm{wt} \%$ relative to swollen composite. The SEM images confirmed complete and uniform distribution of BC nanofibers in the hydrogel matrix. A significant improvement in mechanical properties was achieved. Comparing the PHEMA matrix and $\mathrm{BC}$ with the composite containing $10 \mathrm{wt} \%$ of $\mathrm{BC}$, the tensile strength increased by factors of 80 and 10, respectively, and Young modulus by factors of 120 and 40, respectively. By varying the composition of BC-PHEMA composites, the mechanical properties can be adjusted to achieve the mechanical requirements of soft and semisoft native tissues. Biocompatibility tests demonstrated that BC-PHEMA composites are nontoxic providing a favorable environment for rMSCs proliferation. Therefore, our composites can be seen as promising for application in the tissue engineering area, particularly in tissue replacement and wound healing. 


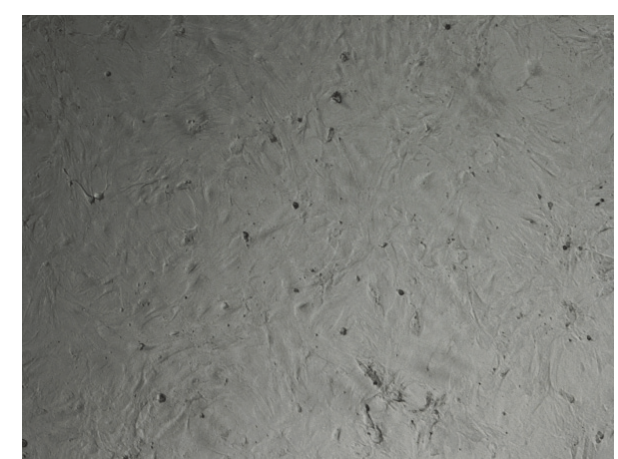

(a)

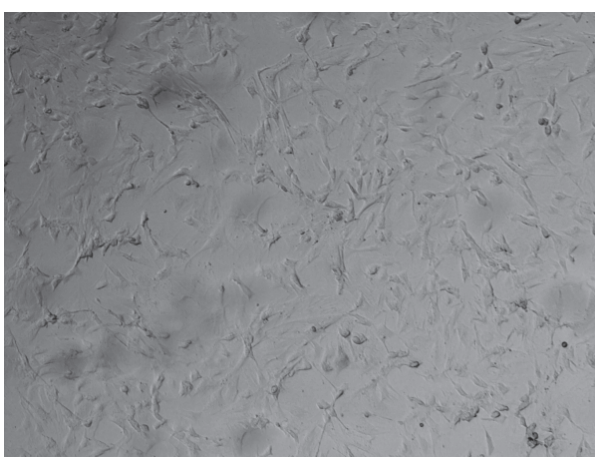

(c)

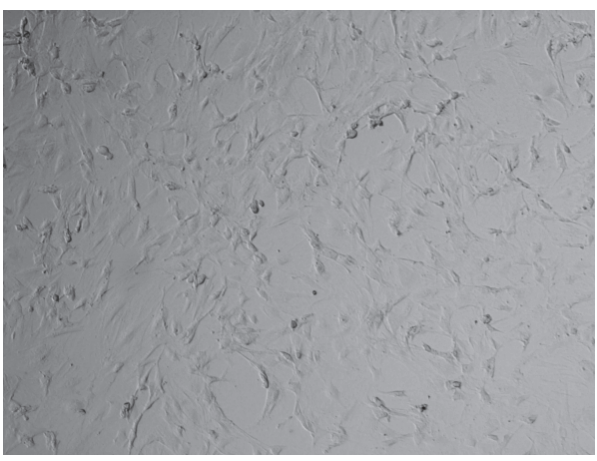

(e)

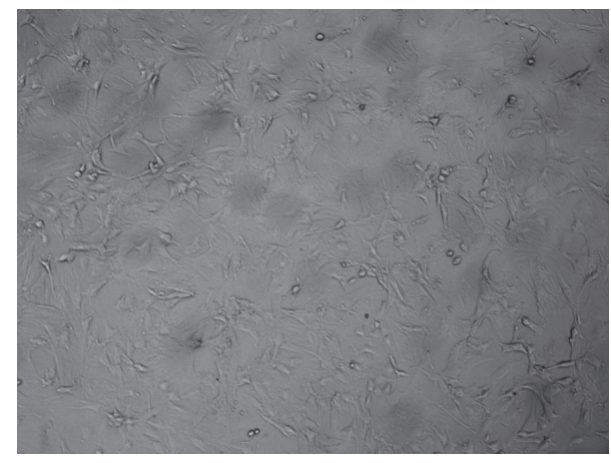

(b)

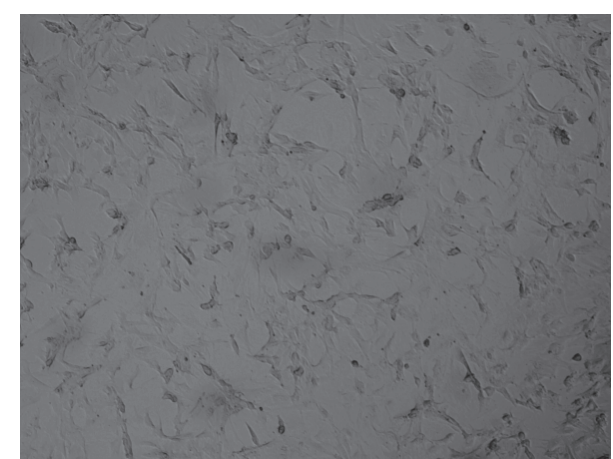

(d)

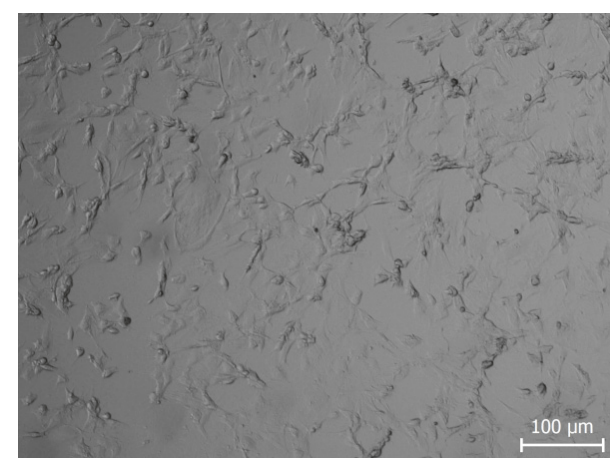

(f)

FIGURE 14: Light microscopy images of morphology of growing rMSCs at $72 \mathrm{~h}$ after seeding in the presence of (a) BC, (b) PHEMA matrix, and BC-PHEMA composites (c) C5, (d) C10, and (e) C20. Image (f) represents a controlling cell growth. Scale bar $100 \mu \mathrm{m}$ is the same for all images.

\section{Conflicts of Interest}

The authors declare that there are no conflicts of interest regarding the publication of this paper.

\section{Acknowledgments}

This work was supported by the Grant Agency of the Czech Republic (Project 16-04863S) and by the Ministry of Education, Youth and Sports of the Czech Republic within the National Sustainability Program II (Project BIOCEV-FAR LQ1604) and the Project "BIOCEV" (CZ.1.05/1.1.00/02.0109). The authors thank Jiri Hodan for measuring the tensile mechanical properties and Dr. Miroslav Slouf for microscopy measurements. Professor Karel Dusek is acknowledged for his contribution to the article finalization.

\section{References}

[1] D. Klemm, F. Kramer, S. Moritz et al., "Nanocelluloses: a new family of nature-based materials," Angewandte Chemie International Edition, vol. 50, no. 24, pp. 5438-5466, 2011.

[2] I. Siró and D. Plackett, "Microfibrillated cellulose and new nanocomposite materials: a review," Cellulose, vol. 17, no. 3, pp. 459-494, 2010.

[3] J. M. Rajwade, K. M. Paknikar, and J. V. Kumbhar, "Applications of bacterial cellulose and its composites in biomedicine," Applied Microbiology and Biotechnology, vol. 99, no. 6, pp. 24912511, 2015. 
[4] Y. Dahman, "Nanostructured biomaterials and biocomposites from bacterial Cellulose nanofibers," Journal of Nanoscience and Nanotechnology, vol. 9, no. 9, pp. 5105-5122, 2009.

[5] N. Hoenich, "Cellulose for medical applications: past, present, and future," BioResources, vol. 1, pp. 270-280, 2006.

[6] S. Thomas, "A review of the physical, biological and clinical properties of a bacterial cellulose wound," Journal of Wound Care, vol. 17, no. 8, pp. 349-352, 2008.

[7] L. Fu, J. Zhang, and G. Yang, "Present status and applications of bacterial cellulose-based materials for skin tissue repair," Carbohydrate Polymers, vol. 92, no. 2, pp. 1432-1442, 2013.

[8] A. Svensson, E. Nicklasson, T. Harrah et al., "Bacterial cellulose as a potential scaffold for tissue engineering of cartilage," Biomaterials, vol. 26, no. 4, pp. 419-431, 2005.

[9] L. Nimeskern, H. Martínez Ávila, J. Sundberg, P. Gatenholm, R. Müller, and K. S. Stok, "Mechanical evaluation of bacterial nanocellulose as an implant material for ear cartilage replacement," Journal of the Mechanical Behavior of Biomedical Materials, vol. 22, pp. 12-21, 2013.

[10] C. Chang and L. Zhang, "Cellulose-based hydrogels: present status and application prospects," Carbohydrate Polymers, vol. 84, no. 1, pp. 40-53, 2011.

[11] A. Nakayama, A. Kakugo, J. P. Gong et al., "High mechanical strength double-network hydrogel with bacterial cellulose," Advanced Functional Materials, vol. 14, no. 11, pp. 1124-1128, 2004.

[12] S. Yano, H. Maeda, M. Nakajima, T. Hagiwara, and T. Sawaguchi, "Preparation and mechanical properties of bacterial cellulose nanocomposites loaded with silica nanoparticles," Cellulose, vol. 15, no. 1, pp. 111-120, 2008.

[13] S. Yamanaka and J. Sugiyama, "Structural modification of bacterial cellulose," Cellulose, vol. 7, no. 3, pp. 213-225, 2000.

[14] T. Maneerung, S. Tokura, and R. Rujiravanit, "Impregnation of silver nanoparticles into bacterial cellulose for antimicrobial wound dressing," Carbohydrate Polymers, vol. 72, no. 1, pp. 4351, 2008.

[15] S. C. M. Fernandes, C. S. R. Freire, A. J. D. Silvestre, C. Pascoal Neto, and A. Gandini, "Novel materials based on chitosan and cellulose," Polymer International, vol. 60, no. 6, pp. 875-882, 2011.

[16] S. Gea, E. Bilotti, C. T. Reynolds, N. Soykeabkeaw, and T. Peijs, "Bacterial cellulose-poly(vinyl alcohol) nanocomposites prepared by an in-situ process," Materials Letters, vol. 64, no. 8, pp. 901-904, 2010.

[17] L. E. Millon, C. J. Oates, and W. Wan, "Compression properties of polyvinyl alcohol-bacterial cellulose nanocomposite," Journal of Biomedical Materials Research Part B: Applied Biomaterials, vol. 90, no. 2, pp. 922-929, 2009.

[18] E. Trovatti, L. Oliveira, C. S. R. Freire et al., "Novel bacterial cellulose-acrylic resin nanocomposites," Composites Science and Technology, vol. 70, no. 7, pp. 1148-1153, 2010.

[19] F. Kramer, D. Klemm, D. Schumann et al., "Nanocellulose polymer composites as innovative pool for (Bio)material development," Macromolecular Symposia, vol. 244, pp. 136-148, 2006.

[20] A. G. P. R. Figueiredo, A. R. P. Figueiredo, A. Alonso-Varona et al., "Biocompatible bacterial cellulose-poly(2-hydroxyethyl methacrylate) nanocomposite films," BioMed Research International, vol. 2013, Article ID 698141, pp. 1-14, 2013.

[21] R. Hobzova, M. Duskova-Smrckova, J. Michalek, E. Karpushkin, and P. Gatenholm, "Methacrylate hydrogels reinforced with bacterial cellulose," Polymer International, vol. 61, no. 7, pp. 1193-1201, 2012.
[22] W. Zhao, Z. Shi, X. Chen, G. Yang, C. Lenardi, and C. Liu, "Microstructural and mechanical characteristics of PHEMAbased nanofibre-reinforced hydrogel under compression," Composites Part B: Engineering, vol. 76, pp. 292-299, 2015.

[23] A. R. P. Figueiredo, A. G. P. R. Figueiredo, N. H. C. S. Silva et al., "Antimicrobial bacterial cellulose nanocomposites prepared by in situ polymerization of 2-aminoethyl methacrylate," Carbohydrate Polymers, vol. 123, pp. 443-453, 2015.

[24] A. L. Buyanov, I. V. Gofman, L. G. Revel'skaya, A. K. Khripunov, and A. A. Tkachenko, "Anisotropic swelling and mechanical behavior of composite bacterial cellulose-poly(acrylamide or acrylamide-sodium acrylate) hydrogels," Journal of the Mechanical Behavior of Biomedical Materials, vol. 3, no. 1, pp. 102-111, 2010.

[25] Y. Hagiwara, A. Putra, A. Kakugo, H. Furukawa, and J. P. Gong, "Ligament-like tough double-network hydrogel based on bacterial cellulose," Cellulose, vol. 17, no. 1, pp. 93-101, 2010.

[26] M. Pandey, N. Mohamad, and M. C. I. M. Amin, "Bacterial cellulose/acrylamide $\mathrm{pH}$-sensitive smart hydrogel: Development, characterization, and toxicity studies in ICR mice model," Molecular Pharmaceutics, vol. 11, no. 10, pp. 3596-3608, 2014.

[27] M. L. Tanaka, N. Vest, C. M. Ferguson, and P. Gatenholm, "Comparison of biomechanical properties of native menisci and bacterial cellulose implant," International Journal of Polymeric Materials and Polymeric Biomaterials, vol. 63, no. 17, pp. 891897, 2014

[28] H. Martínez Ávila, S. Schwarz, E.-M. Feldmann et al., "Biocompatibility evaluation of densified bacterial nanocellulose hydrogel as an implant material for auricular cartilage regeneration," Applied Microbiology and Biotechnology, vol. 98, no. 17, pp. 7423-7435, 2014.

[29] J. Michalek, M. Pradny, and K. Dusek, "Hydrogels in biology and medicine," Bioceramics Development and Applications, pp. 177-230, 2010.

[30] J. Labsky, J. Vacik, and P. Hosek, Preparations for Prevention And Healing of Inflammation Affections, US6610284-B1, 2003.

[31] A. Bodin, H. Bäckdahl, H. Fink, L. Gustafsson, B. Risberg, and P. Gatenholm, "Influence of cultivation conditions on mechanical and morphological properties of bacterial cellulose tubes," Biotechnology and Bioengineering, vol. 97, no. 2, pp. 425434, 2007.

[32] I. Breßler, J. Kohlbrecher, and A. F. Thünemann, "SASfit: A tool for small-angle scattering data analysis using a library of analytical expressions," Journal of Applied Crystallography, vol. 48, pp. 1587-1598, 2015.

[33] C. Azuma, K. Yasuda, Y. Tanabe et al., "Biodegradation of hightoughness double network hydrogels as potential materials for artificial cartilage," Journal of Biomedical Materials Research Part A, vol. 81A, no. 2, pp. 373-380, 2007.

[34] L. Ambrosio, R. De Santis, S. Iannace, P. A. Netti, and L. Nicolais, "Viscoelastic behavior of composite ligament prostheses," Journal of Biomedical Materials Research Part B: Applied Biomaterials, vol. 42, no. 1, pp. 6-12, 1998.

[35] P. Netti, A. D’Amore, D. Ronca, L. Ambrosio, and L. Nicolais, "Structure-mechanical properties relationship of natural tendons and ligaments," Journal of Materials Science: Materials in Medicine, vol. 7, no. 9, pp. 525-530, 1996. 


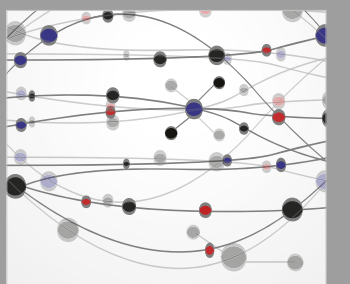

The Scientific World Journal
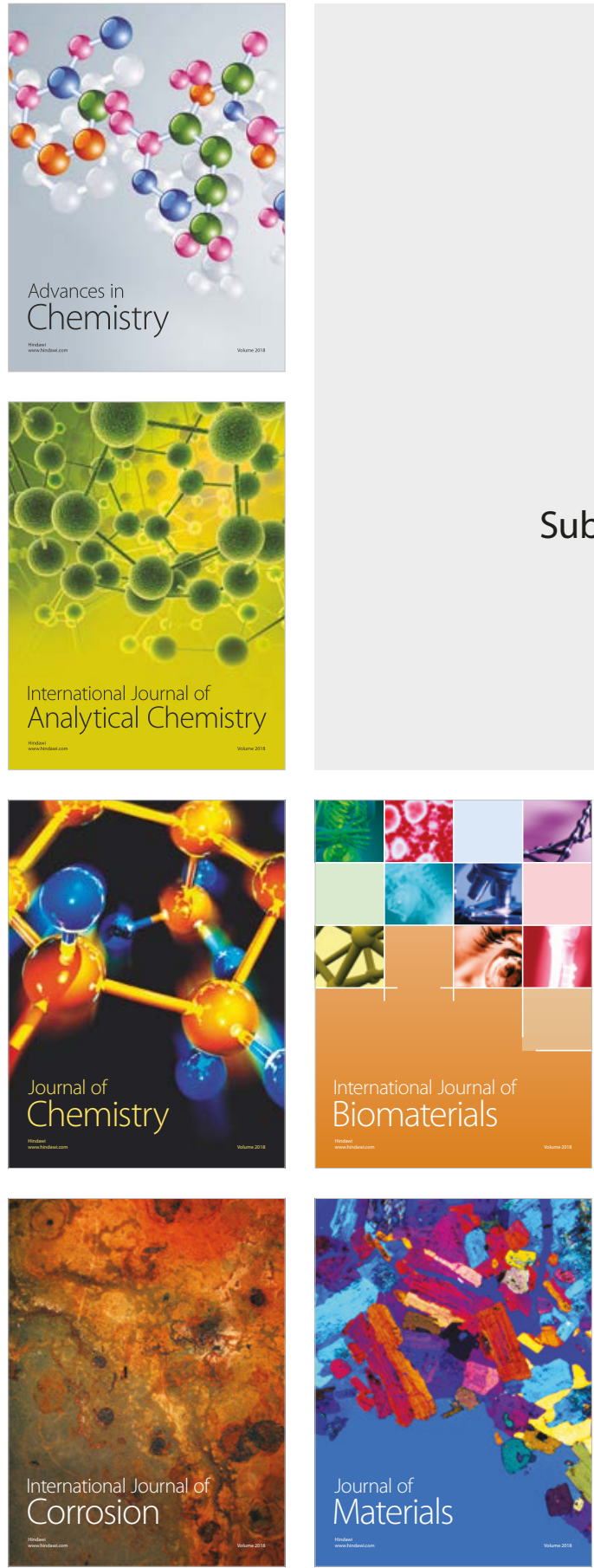

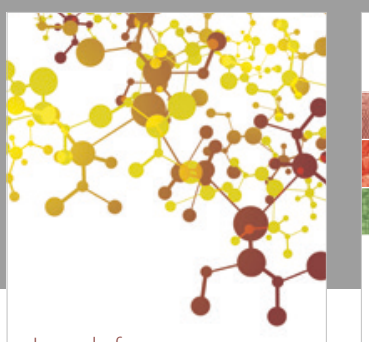

Journal of

Applied Chemistry
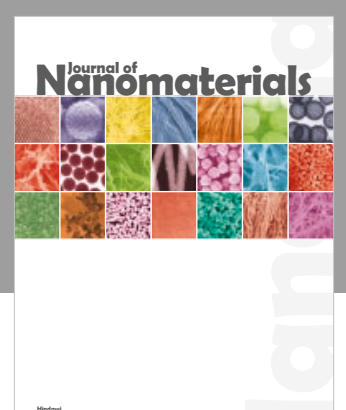

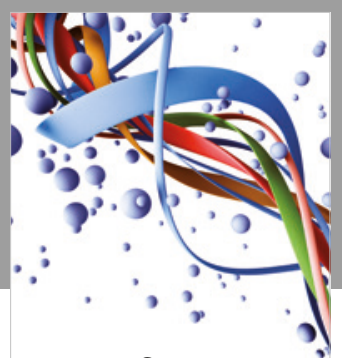

Scientifica

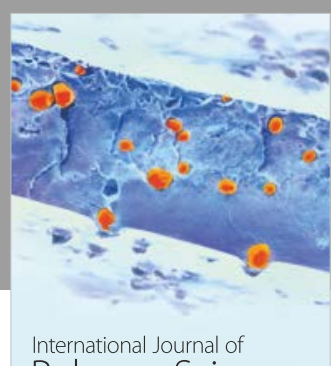

Polymer Science

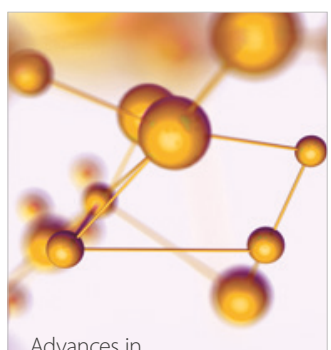

Physical Chemistry
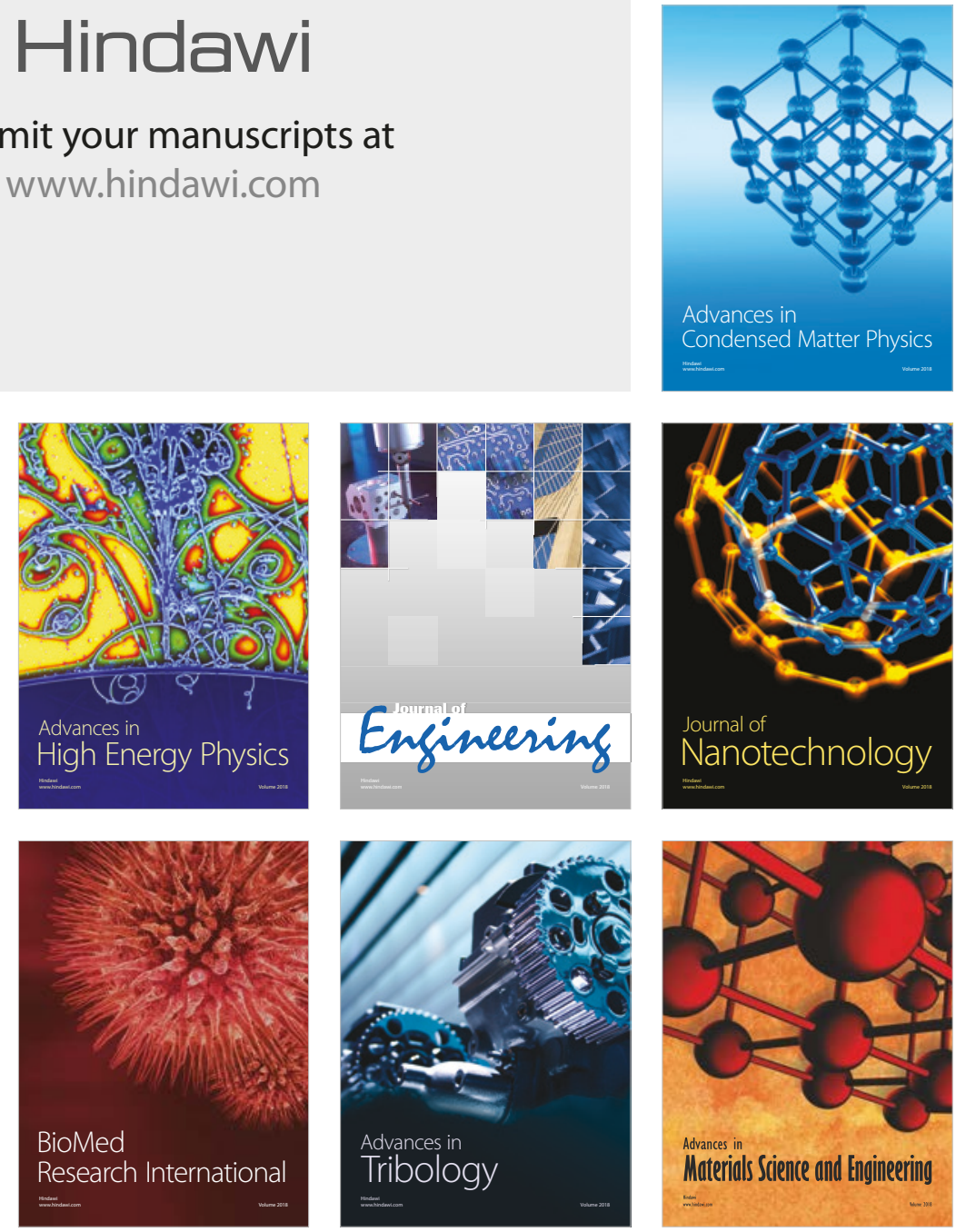